\title{
Erratum to: Chemical Condensation Wave Initiating Oxygen-Free Combustion and Detonation
}

\author{
A. V. Emelianov ${ }^{a}$, A. V. Eremin ${ }^{a, *}$, and V. E. Fortov ${ }^{a}$ \\ a Joint Institute for High Temperatures, Russian Academy of Sciences, Moscow, 125412 Russia \\ *e-mail: eremin@jiht.ru \\ Received October 29, 2021; revised October 29, 2021; accepted October 29, 2021
}

DOI: $10.1134 /$ S1990793121300011

The article "Chemical Condensation Wave Initiating Oxygen-Free Combustion and Detonation", written by A. V. Emelianov, A. V. Eremin, and V. E. Fortov, was originally published electronically in Springer-Link on 23 June 2021 without Open Access. After publication in volume 15, issue 2, pages 299-306 the authors decided to make the article an Open Access publication. Therefore, the copyright of the article has been changed to (C) The Author(s) 2021 and the article is forthwith distributed under the terms of a Creative Commons Attribution 4.0 International License (http://creativecommons.org/licenses/by/4.0/, CC BY), which permits use, duplication, adaptation, distribution and reproduction of a work in any medium or format, as long as you cite the original author(s) and publication source, provide a link to the Creative Commons license, and indicate if changes were made.

The original article can be found online at https://doi.org/10.1134/S1990793121020160 